Case Report

\title{
Diabetic Dead-in-Bed Syndrome: A Possible Link to a Cardiac Ion Channelopathy
}

\author{
Jonathan R. Skinner, ${ }^{1,2,3}$ Renate Marquis-Nicholson, ${ }^{4,5}$ Alix Luangpraseuth, ${ }^{6,7}$ \\ Rick Cutfield, ${ }^{8}$ Jackie Crawford, ${ }^{1}$ and Donald R. Love ${ }^{1,4,6}$ \\ ${ }^{1}$ Cardiac Inherited Disease Group, Auckland City Hospital, Auckland 1148, New Zealand \\ ${ }^{2}$ Green Lane Paediatric and Congenital Cardiac Services, Starship Children's Hospital, Auckland 1148, New Zealand \\ ${ }^{3}$ Department of Child Health, University of Auckland, Private Bag 92019, Auckland 1142, New Zealand \\ ${ }^{4}$ Diagnostic Genetics, LabPlus, Auckland City Hospital, Auckland 1148, New Zealand \\ ${ }^{5}$ Department of Pathology, University of Melbourne, Parkville, VIC 3010, Australia \\ ${ }^{6}$ School of Biological Sciences, University of Auckland, Private Bag 92019, Auckland 1142, New Zealand \\ ${ }^{7}$ INRA, UMR 1198, Biologie du Développement et Reproduction, 78350 Jouy-en-Josas, France \\ ${ }^{8}$ Diabetes Service, North Shore Hospital, Takapuna, Auckland 0622, New Zealand
}

Correspondence should be addressed to Donald R. Love; donaldl@adhb.govt.nz

Received 18 September 2013; Accepted 7 January 2014; Published 19 February 2014

Academic Editor: Michael S. Firstenberg

Copyright (C) 2014 Jonathan R. Skinner et al. This is an open access article distributed under the Creative Commons Attribution License, which permits unrestricted use, distribution, and reproduction in any medium, provided the original work is properly cited.

Sudden unexpected nocturnal death among patients with diabetes occurs approximately ten times more commonly than in the general population. Malignant ventricular arrhythmia due to Brugada syndrome has been postulated as a cause, since a glucoseinsulin bolus can unmask the Brugada electrocardiographic signature in genetically predisposed individuals. In this report we present a 16-year-old male with insulin-dependent diabetes who died suddenly at night. His diabetes had been well controlled, without significant hypoglycaemia. At autopsy, he had a full stomach and a glucose level of $7 \mathrm{mmol} / \mathrm{L}$ in vitreous humor, excluding hypoglycaemia. Genetic analysis of autopsy DNA revealed a missense mutation, c.370A>G (p.Ile124Val), in the GPD1L gene. A parent carried the same mutation and has QT prolongation. Mutations in this gene have been linked to Brugada syndrome and sudden infant death. The patient may have died from a ventricular arrhythmia, secondary to occult Brugada syndrome, triggered by a full stomach and insulin. The data suggest that molecular autopsies are warranted to investigate other cases of the diabetic dead-in-bed syndrome.

\section{Introduction}

Sudden unexpected nocturnal death among patients with diabetes is greatly feared and poorly understood, occurring approximately ten times more commonly than in the general population [1]. The "dead-in-bed" syndrome, by definition, has a negative autopsy and accounts for up to $6 \%$ of all deaths in type I diabetics under the age of 40 years [2]. Hypoglycaemia has been put forward as the most likely explanation but has been excluded in some cases [2-4]. The possibility that a cardiac ion channelopathy such as long QT syndrome or Brugada syndrome may cause death through a malignant arrhythmia in individuals with diabetes has been considered but never proven [5].

We report the postmortem molecular genetic investigation of a 16-year-old boy with type 1 diabetes who died in his sleep. His blood glucose had been well-controlled; he had a full stomach at autopsy and a glucose level in vitreous humor of $7 \mathrm{mmol} / \mathrm{L}$. These features argue strongly against hypoglycaemia. Molecular genetic investigation revealed a missense mutation (p.Ile124Val) in the GPD1L gene. GPD1$\mathrm{L}$ catalyses the conversion of sn-glycerol 3-phosphate to glycerone phosphate and binds to the SCN5A ion channel protein; mutations in the GPDIL gene have been linked to 


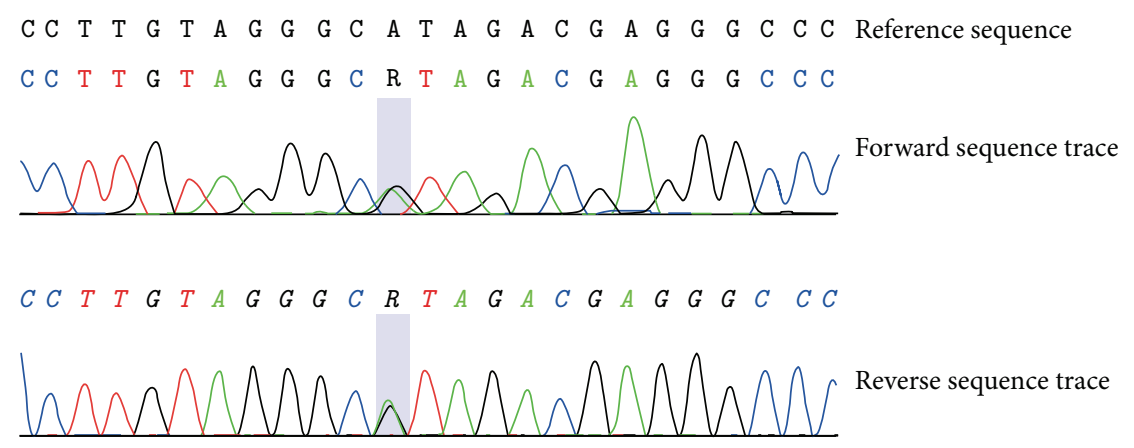

Figure 1: Sequence analysis of proband. Sequence electropherograms show the presence of the c.370A $>$ G, p.Ile124Val (p.I124V), mutation in exon 4 of the GPD1L gene.

Brugada syndrome and to sudden infant death syndrome [6$8]$.

\section{Case History}

The boy was diagnosed as having type 1 diabetes at the age of 15 years (nine months prior to his death) presenting with mild diabetic ketoacidosis following a nine-month history of polydipsia and polyuria. He was managed with insulin and at the time of his death was receiving four injections per day: insulin aspart three times daily (approximately 12 units at meals, varied by carbohydrate load and prevailing blood sugar level) and insulin glargine 30 units at bed time. Three months prior to his death, his HbAlc level was 7.3\% $(56 \mathrm{mmol} / \mathrm{mL})$. He was fully compliant with therapy and home glucose monitoring, and he remained physically active and fit. Review of his monitoring book and history revealed no episodes of severe hypoglycaemia or obvious nocturnal hypoglycaemia. On the evening prior to his death he had been completely well, had a normal full meal, had his insulin, and went to bed as usual at approximately 9:30 p.m. He was found dead the following morning lying face down on his bed and could not be resuscitated. He had no previous history of syncope or seizure and never had cause to have any cardiac tests during his life.

At autopsy, there were no pathological findings to indicate a cause of death. Cardiac and cerebral examinations were normal. Significantly, however, he had a full stomach, suggesting that he died soon after his meal. A standard toxicology screen was negative. The glucose level in his vitreous humor excluded hypoglycaemia at $7 \mathrm{mmol} / \mathrm{L}$ (126 mg/dL) [9]. DNA was extracted and stored from a peripheral blood sample and the family was referred for cardiac genetic investigation as is routine in New Zealand for sudden unexplained deaths between one and 40 years of age [10].

\section{Molecular Analysis of Postmortem Sample}

The coding regions for those genes linked to Long QT syndrome types $1,2,3,5,6$, and 7 were amplified and subjected to capillary-based sequencing, as described earlier [11], but no mutations were identified. Amplification of the coding regions of the GPD1L gene (Refseq accession number

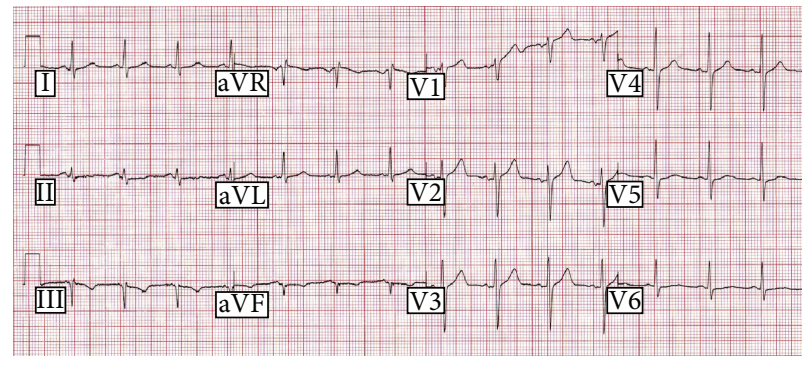

FIGURE 2: 12-lead electrocardiagram of the deceased's father. The STT segment is unusual and very flat in lead II, such that determining the end of the T wave is difficult. In lead I, R-R is $690 \mathrm{~ms}$, QT is $396 \mathrm{~ms}$, and QTc is $477 \mathrm{~ms}$. In lead V5, R-R is $711 \mathrm{~ms}$, QT s $391 \mathrm{~ms}$, and QTc is $464 \mathrm{~ms}$; the T wave is of low amplitude with a slight double bump morphology.

NM_015141.3; primer designs based on [12]) and subsequent sequencing revealed a heterozygous missense mutation in exon 4: c.370A > G, p.Ile124Val (Figure 1).

\section{Family Investigation}

There was no known history of sudden death in the family. Both parents and his only sibling were investigated. 12 lead ECGs were normal in the mother and sibling. Exercise testing and cardiac magnetic resonance imaging were normal in the mother. The father's ECG showed subtly abnormal repolarisation with a marginally prolonged QT interval; the heart-rate corrected QT interval (QTc) was 0.46 seconds (on no medication) (Figure 2). The maternal aunt had a history of syncope that sounded vasovagal in nature. Her ECG, exercise testing, and cardiac magnetic resonance imaging tests were normal.

After genetic counselling, DNA was obtained from the father, mother and sister and these were tested for the presence of the mutation c.370A $>$ G, p.Ile124Val, in the GPD1L gene. The father carried the mutation, whereas the mother, and sibling did not. Pharmacological challenge to the cardiac sodium channel was performed on the father using intravenous ajmaline at $1 \mathrm{mg} / \mathrm{kg}$ over ten minutes. No evidence of Brugada signature was unmasked. 
TABLE 1: In silico analysis of GPD1L gene* mutation.

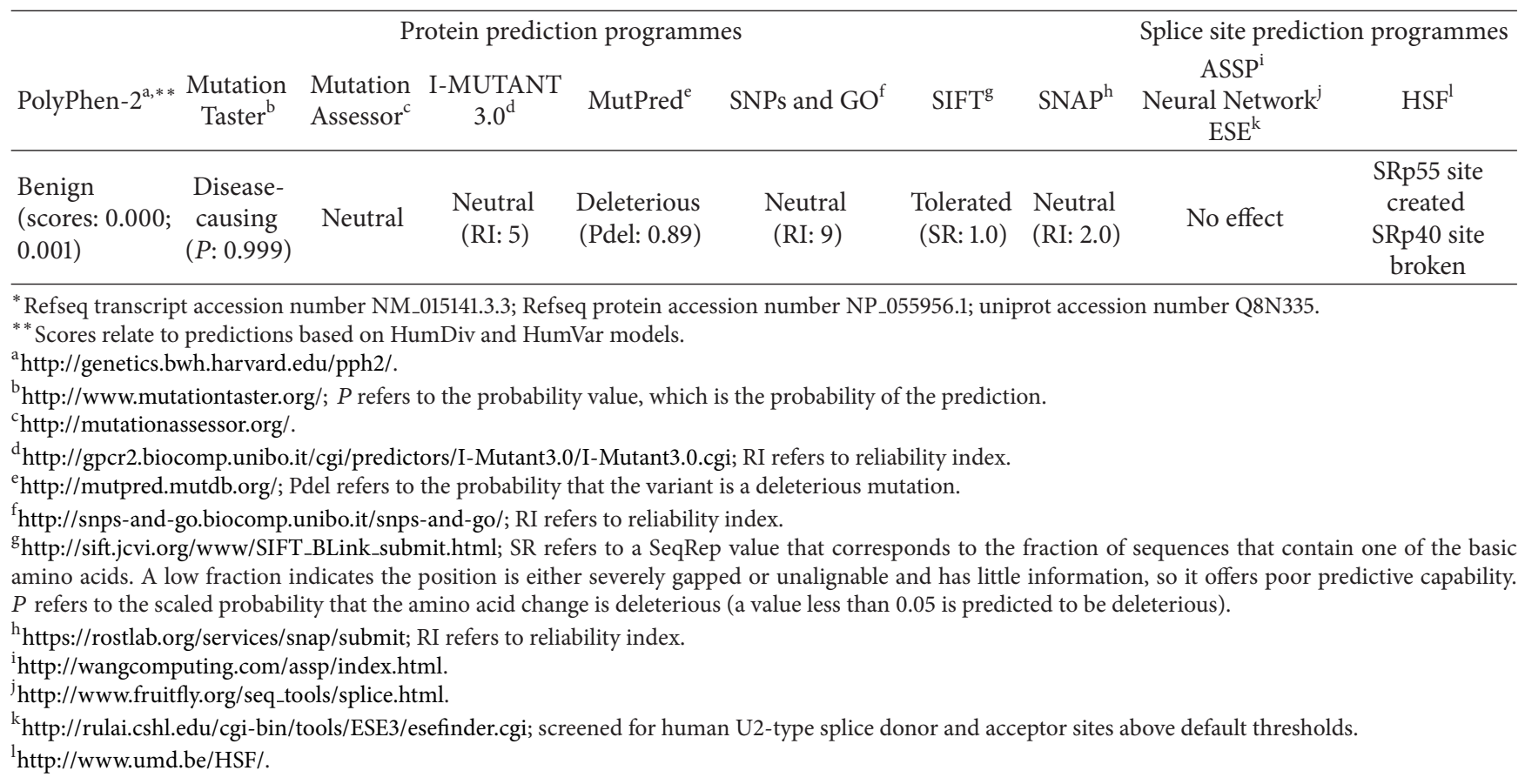

\section{Discussion}

This case suggests a cause of death in a patient with diabetes who died in bed with a negative autopsy. It demonstrates a possible link between dead-in-bed syndrome and Brugada syndrome, thereby supporting earlier work [13], albeit for a GPD1L gene variant of unclear clinical significance but with supportive in vitro evidence.

Cardiac ion channelopathies explain 20 to $40 \%$ of autopsy negative sudden death in 1-40-year-olds [10, 14-16]. Most such deaths in this age group occur at rest or during sleep, and these diagnoses are reached by cardiac/genetic investigation of either autopsy DNA or living family members. Mutations in the GPD1L gene were first reported in 2007 to be causative of sudden infant death and familial Brugada syndrome [6, 7]. GPD1L has a functional link with the cardiac sodium channel $\mathrm{Na}_{\mathrm{v}} 1.5$ [7], which is encoded for by the SCN5A gene. Mutations in the latter gene are the most common single cause of sudden infant death syndrome (SIDS) and familial Brugada syndrome. They also cause long QT syndrome type 3. Death is due to ventricular fibrillation or ventricular tachycardia.

Death during sleep, most commonly in young males, is typical in Brugada syndrome and Long QT type 3, both of which are caused by dysfunction of the cardiac sodium ion channel $\mathrm{Na}_{\mathrm{v}} 1.5$ [17]. Long QT syndrome and Brugada syndrome can occur with the same mutation, even in the same family with age, heart rate, fever, and other developmental or environmental influences playing a role (cardiac sodium channel overlap syndrome) [17].

In Brugada syndrome a diagnostic cardiac depolarization abnormality is seen on the 12-lead ECG with right-bundle branch block appearance in V1 and V2 associated with ST elevation [18]. In genetically predisposed children, fever is a potent trigger for malignant arrhythmias [19, 20].

There is some conflicting evidence regarding the pathogenicity of the mutation reported here. I $124 \mathrm{~V}$ was initially discovered in a 5-week-old infant who died suddenly and had a negative postmortem examination [7]. The mutation is in a highly conserved residue and, when coexpressed in vitro with SCN5A in heterologous HEK cells (Human Embryonic Kidney 293 cells), produces a significantly reduced sodium channel current [7]. The NCBI database records the variant as likely pathogenic (http://www.ncbi.nlm.nih.gov/clinvar/? term=rs72552293; entry dated August 18, 2011). In contrast, bioinformatic analysis of the mutation event at the protein level predicts a benign as well as a disease-causing effect, while three programmes predict no effect regarding splicing of the GPDIL gene transcript and one predicts an effect on SR protein binding sites (Table 1). SR proteins can influence splice site selection [21-25], but transcript analysis of the GPD1L gene has not been undertaken in the case reported here. The c.370A $>\mathrm{G}$ variant has been reported at frequencies of $0.14 \%$ and $0.11 \%$ in the 1000 Genomes project and GO-ESP databases, respectively. These data suggest that the variant is present in nominally unaffected individuals and so may be nonpathogenic.

It is interesting that the father, who carries the same mutation, had a negative ajmaline challenge. Ajmaline is a cardiac sodium channel blocker, and $75-80 \%$ of Brugada syndrome mutation carriers can be unmasked by it [26]. Variable clinical expression of these mutations is common, possibly due to the effect of common polymorphisms within the same gene or in SCN5A [27]. However, the father does have a marginally prolonged QT interval. 
Supportive evidence for a link between the diabetic deadin-bed syndrome and cardiac sodium channel dysfunction comes from a recent report from an adult male with diabetes [28]. He displayed a Brugada signature on his ECG during hyperglycaemic and hyperkalaemic ketoacidosis and his son also had Brugada syndrome. The authors postulated that the biochemical disturbances were to blame for transient cardiac sodium channel blockade in a genetically predisposed individual.

A large meal also unmasks the Brugada sign in genetically predisposed individuals. Ikeda et al. [29] showed that the "full stomach test" was positive in half of the subjects evaluated, and the appearance of the Brugada sign with a full stomach was more likely in those with a history of malignant arrhythmia. In addition, glucose infusion followed by insulin injection unmasks the Brugada sign $[30,31]$. Thus, the full stomach found in our patient not only makes hypoglycaemia very unlikely but also supports the suggestion that he died from Brugada syndrome.

Another group has looked for genetic abnormalities in patients with diabetes who have died suddenly. Tu et al. [5] studied DNA retrospectively from 22 such cases and found no mutations in either the $S C N 5 A$ gene or the G6PC, $P H O X 2 B$, and $C T G F$ genes. The latter three genes are involved in gluconeogenesis/glycogenolysis, dysautonomia, and endothelial cell function, respectively; however, they did not analyze the GPD1L gene or any of the other Long QT genes. Further, they had to use DNA extracted from less robust sources such as paraffin embedded tissue blocks, where complete analysis is rarely possible.

The death of this 16-year-old boy presumably occurred due to a malignant ventricular arrhythmia caused by the combination of a genetic predisposition to occult cardiac Brugada syndrome and an electrolyte disturbance brought about by a full stomach and a high level of insulin. This case raises the possibility that some other young people with diabetes who have died unexpectedly at night will have done so due to a coexistent inherited arrhythmic predisposition. This might include long QT syndrome, for example, since hypoglycaemia is known to be potentially proarrhythmic in diabetes through QT interval prolongation and intracellular calcium overload [32].

Prevention of deaths in inherited arrhythmic syndromes is possible, but a diagnosis has first to be made. Given the proarrhythmic events explained above, which occur in patients with diabetes, an argument presents itself for obtaining a family history for young sudden death or arrhythmic syndromes, and a 12 lead ECG in every case. We suggest that good quality DNA should be retained following sudden death of a young person with diabetes, as should be standard practice for any sudden unexplained natural death in the young $[33,34]$. If a conclusive cause of death is not found, the family should be referred to a cardiac genetic service, and genetic screening of autopsy DNA for cardiac ion channelopathies, particularly Brugada syndrome, should be considered. A molecular genetic cause of death can be made from DNA even when a blood sample (such as stored on a Guthrie card) is over 30 years old [16].

\section{Abbreviations}

CTGF: Gene encoding for connective tissue growth factor

G6PC: Gene encoding for glucose-6-phosphatase

GPD1L: Gene glycerol-3-phosphate dehydrogenase 1-like protein

PHOX2B: Gene encoding for paired mesoderm homeobox protein $2 \mathrm{~b}$

SCN5A: Gene encoding for sodium channel protein type 5 subunit alpha, isoform a

$\mathrm{Na}_{\mathrm{v}}$ 1.5: Sodium ion channel protein, voltage-gated, type V, alpha subunit.

\section{Conflict of Interests}

All authors have no conflict of interests to disclose.

\section{Acknowledgments}

The authors are most grateful for the family's support and permission to report this tragic case. The authors thank Dr. Tim Koelmeyer forensic pathologist (now retired) for his foresight in referring the case for investigation. A part of the genetic testing costs and Dr. Skinner's salary were funded by Cure Kids. The sponsorship is in the form of a nondirective grant; Cure Kids had no role in study design or any other aspect of this report.

\section{References}

[1] A. M. Secrest, D. J. Becker, S. F. Kelsey, R. E. Laporte, and T. J. Orchard, "Characterizing sudden death and dead-in-bed syndrome in type 1 diabetes: analysis from two childhood-onset type 1 diabetes registries," Diabetic Medicine, vol. 28, no. 3, pp. 293-300, 2011.

[2] O. Sovik and H. Thordarson, "Dead-in-bed syndrome in young diabetic patients," Diabetes Care, vol. 22, supplement 2, pp. B40B42, 1999.

[3] H. Thordarson and O. Sovik, "Dead in bed syndrome in young diabetic patients in Norway," Diabetic Medicine, vol. 12, no. 9, pp. 782-787, 1995.

[4] E. Tu, S. M. Twigg, J. Duflou, and C. Semsarian, "Causes of death in young Australians with type 1 diabetes: a review of coronial postmortem examinations," Medical Journal of Australia, vol. 188, no. 12, pp. 699-702, 2008.

[5] E. Tu, R. D. Bagnall, J. Duflou, M. Lynch, S. M. Twigg, and C. Semsarian, "Post-mortem pathologic and genetic studies in "dead in bed syndrome" cases in type 1 diabetes mellitus," Human Pathology, vol. 41, no. 3, pp. 392-400, 2010.

[6] B. London, M. Michalec, H. Mehdi et al., "Mutation in glycerol3-phosphate dehydrogenase 1-like gene (GPD1-L) decreases cardiac $\mathrm{Na}^{+}$current and causes inherited arrhythmias," Circulation, vol. 116, no. 20, pp. 2260-2268, 2007.

[7] D. W. van Norstrand, C. R. Valdivia, D. J. Tester et al., "Molecular and functional characterization of novel glycerol-3-phosphate dehydrogenase 1-like gene (GPD1-L) mutations in sudden infant death syndrome," Circulation, vol. 116, no. 20, pp. 2253-2259, 2007. 
[8] P. L. Hedley, P. Jørgensen, S. Schlamowitz et al., "The genetic basis of brugada syndrome: a mutation update," Human Mutation, vol. 30, no. 9, pp. 1256-1266, 2009.

[9] J. Hockenhull, W. Dhillo, R. Andrews, and S. Paterson, "Investigation of markers to indicate and distinguish death due to alcoholic ketoacidosis, diabetic ketoacidosis and hyperosmolar hyperglycemic state using post-mortem samples," Forensic Science International, vol. 214, no. 1-3, pp. 142-147, 2012.

[10] J. R. Skinner, J. Crawford, W. Smith et al., "Prospective, population-based long QT molecular autopsy study of postmortem negative sudden death in 1 to 40 year olds," Heart Rhythm, vol. 8, no. 3, pp. 412-419, 2011.

[11] S. Lai, R. Marquis-Nicholson, C. C. Lan, J. Skinner, and D. R. Love, "Post mortem DNA: QC considerations for sequence and dosage analysis of genes implicated in Long QT syndrome," in Latest Research into Quality Control 2, I. Akyar, Ed., chapter 18, pp. 395-412, IN-TECH, 2012.

[12] D. Lai and D. R. Love, "Automation of a primer design and evaluation pipeline for subsequent sequencing of the coding regions of all human Refseq genes," Bioinformation, vol. 8, no. 8, pp. 363-366, 2012.

[13] M. Vatta, R. Dumaine, G. Varghese et al., "Genetic and biophysical basis of sudden unexplained nocturnal death syndrome (SUNDS), a disease allelic to Brugada syndrome," Human Molecular Genetics, vol. 11, no. 3, pp. 337-345, 2002.

[14] E. R. Behr, C. Dalageorgou, M. Christiansen et al., "Sudden arrhythmic death syndrome: familial evaluation identifies inheritable heart disease in the majority of families," European Heart Journal, vol. 29, no. 13, pp. 1670-1680, 2008.

[15] H. L. Tan, N. Hofman, I. M. van Langen, A. C. van der Wal, and A. A. M. Wilde, "Sudden unexplained death: heritability and diagnostic yield of cardiological and genetic examination in surviving relatives," Circulation, vol. 112, no. 2, pp. 207-213, 2005.

[16] P. A. Gladding, C.-A. Evans, J. Crawford et al., "Posthumous diagnosis of long QT syndrome from neonatal screening cards," Heart Rhythm, vol. 7, no. 4, pp. 481-486, 2010.

[17] C. A. Remme, A. A. M. Wilde, and C. R. Bezzina, "Cardiac sodium channel overlap syndromes: different faces of SCN5A mutations," Trends in Cardiovascular Medicine, vol. 18, no. 3, pp. 78-87, 2008.

[18] C. Antzelevitch, P. Brugada, M. Borggrefe et al., "Brugada syndrome: report of the second consensus conference," Circulation, vol. 111, no. 5, pp. 659-670, 2005.

[19] J. R. Skinner, S.-K. Chung, C.-A. Nel et al., "Brugada syndrome masquerading as febrile seizures," Pediatrics, vol. 119, no. 5, pp. e1206-e1211, 2007.

[20] V. Probst, I. Denjoy, P. G. Meregalli et al., "Clinical aspects and prognosis of Brugada syndrome in children," Circulation, vol. 115, no. 15, pp. 2042-2048, 2007.

[21] J. F. Cáceres, S. Stamm, D. M. Helfman, and A. R. Krainer, "Regulation of alternative splicing in vivo by overexpression of antagonistic splicing factors," Science, vol. 265, no. 5179, pp. 1706-1709, 1994.

[22] X. D. Fu, "The superfamily of arginine/serine-rich splicing factors," RNA, vol. 1, no. 7, pp. 663-680, 1995.

[23] G. R. Screaton, J. F. Caceres, A. Mayeda et al., "Identification and characterization of three members of the human SR family of pre-mRNA splicing factors," The EMBO Journal, vol. 14, no. 17, pp. 4336-4349, 1995.
[24] J. Wang and J. L. Manley, "Overexpression of the SR proteins ASF/SF2 and SC35 influences alternative splicing in vivo in diverse ways," RNA, vol. 1, no. 3, pp. 335-346, 1995.

[25] J. L. Manley and R. Tacke, "SR proteins and splicing control," Genes and Development, vol. 10, no. 13, pp. 1569-1579, 1996.

[26] K. Hong, J. Brugada, A. Oliva et al., "Value of electrocardiographic parameters and ajmaline test in the diagnosis of Brugada syndrome caused by SCN5A mutations," Circulation, vol. 110, no. 19, pp. 3023-3027, 2004.

[27] E. Lizotte, M. J. Junttila, M. P. Dube et al., "Genetic modulation of brugada syndrome by a common polymorphism," Journal of Cardiovascular Electrophysiology, vol. 20, no. 10, pp. 1137-1141, 2009.

[28] P. G. Postema, A. P. J. Vlaar, J. H. Devries, and H. L. Tan, "Familial Brugada syndrome uncovered by hyperkalaemic diabetic ketoacidosis," Europace, vol. 13, no. 10, pp. 1509-1510, 2011.

[29] T. Ikeda, A. Abe, S. Yusu et al., "The full stomach test as a novel diagnostic technique for identifying patients at risk of Brugada syndrome," Journal of Cardiovascular Electrophysiology, vol. 17, no. 6, pp. 602-607, 2006.

[30] M. Nishizaki, H. Sakurada, T. Ashikaga et al., "Effects of glucose-induced insulin secretion on ST segment elevation in the Brugada syndrome," Journal of Cardiovascular Electrophysiology, vol. 14, no. 3, pp. 243-249, 2003.

[31] A. Nogami, M. Nakao, S. Kubota et al., "Enhancement of J-STsegment elevation by the glucose and insulin test in Brugada syndrome," Pacing and Clinical Electrophysiology, vol. 26, no. 1, part 2, pp. 332-337, 2003.

[32] C. Nordin, "The case for hypoglycaemia as a proarrhythmic event: basic and clinical evidence," Diabetologia, vol. 53, no. 8, pp. 1552-1561, 2010.

[33] J. R. Skinner, J. A. Duflou, and C. Semsarian, "Reducing sudden death in young people in Australia and New Zealand: the TRAGADY initiative," Medical Journal of Australia, vol. 189, no. 10, pp. 539-540, 2008.

[34] M. J. Ackerman, S. G. Priori, S. Willems et al., "HRS/EHRA expert consensus statement on the state of genetic testing for the channelopathies and cardiomyopathies: this document was developed as a partnership between the Heart Rhythm Society (HRS) and the European Heart Rhythm Association (EHRA)," Heart Rhythm, vol. 8, no. 8, pp. 1308-1339, 2011. 


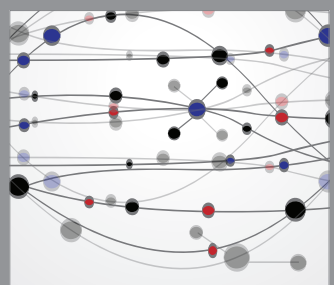

The Scientific World Journal
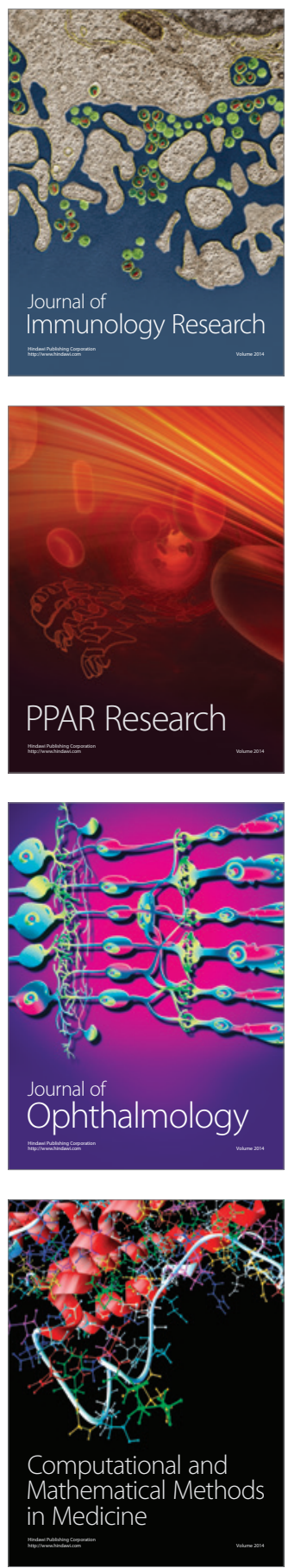

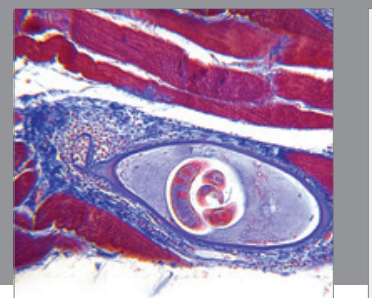

Gastroenterology

Research and Practice
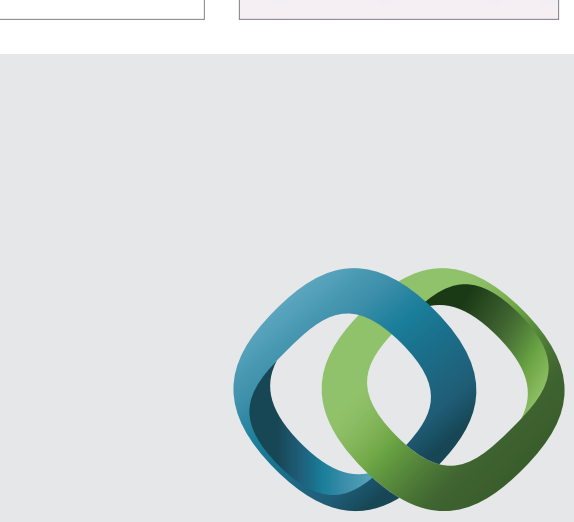

\section{Hindawi}

Submit your manuscripts at

http://www.hindawi.com
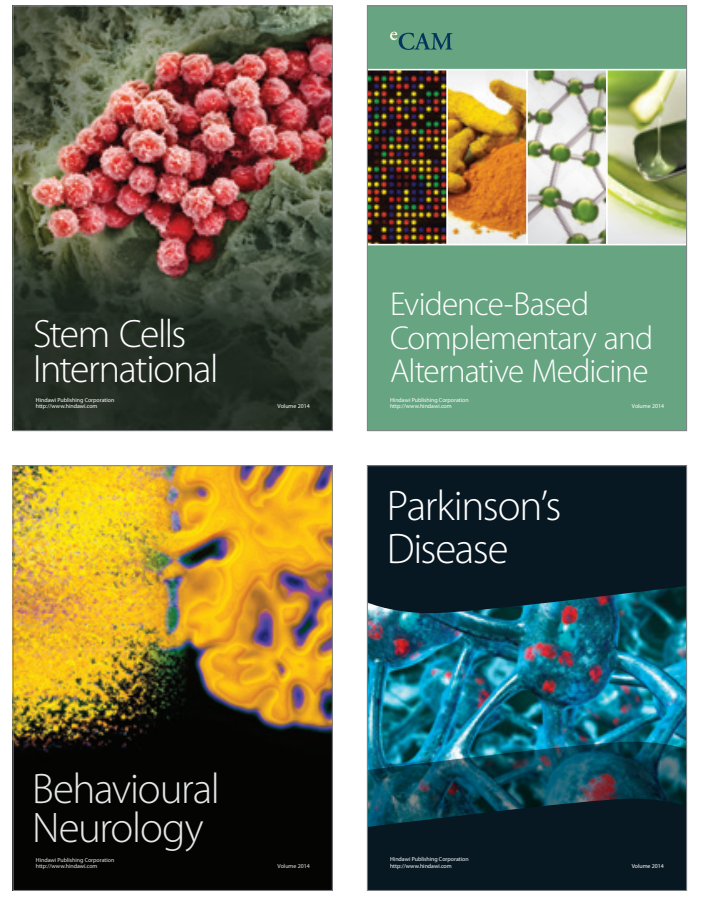
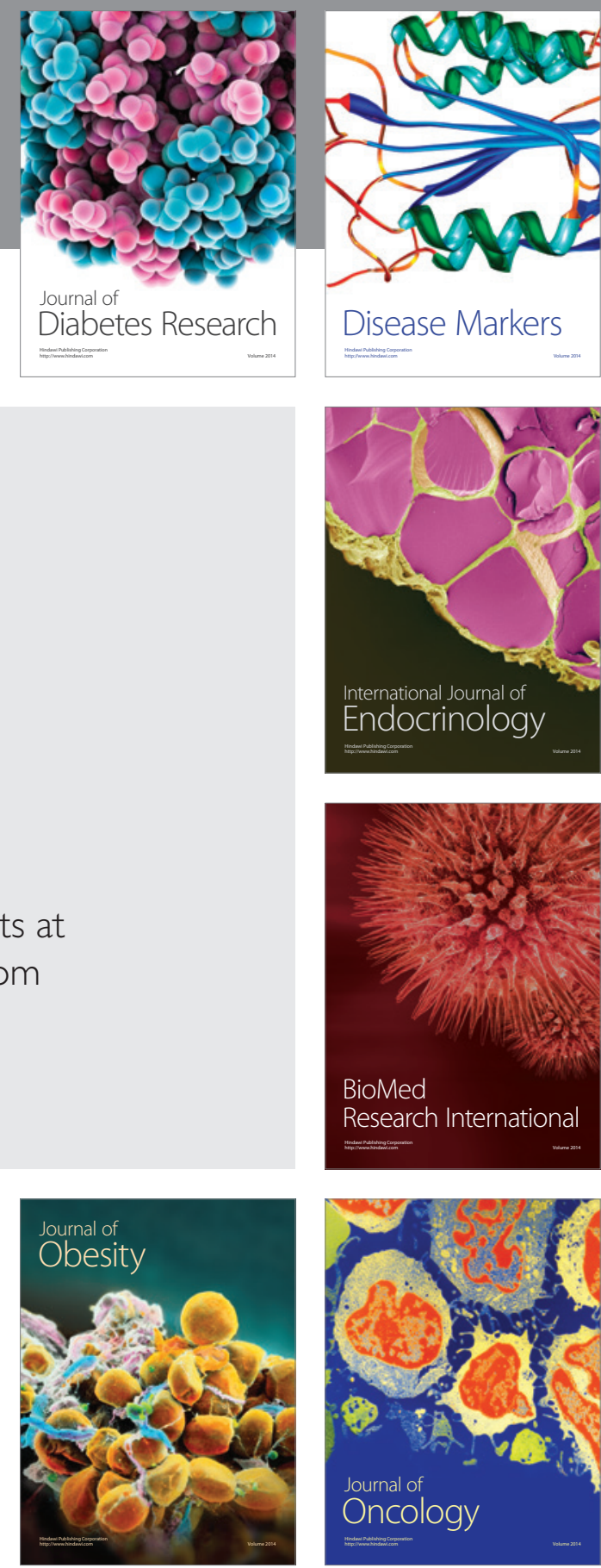

Disease Markers
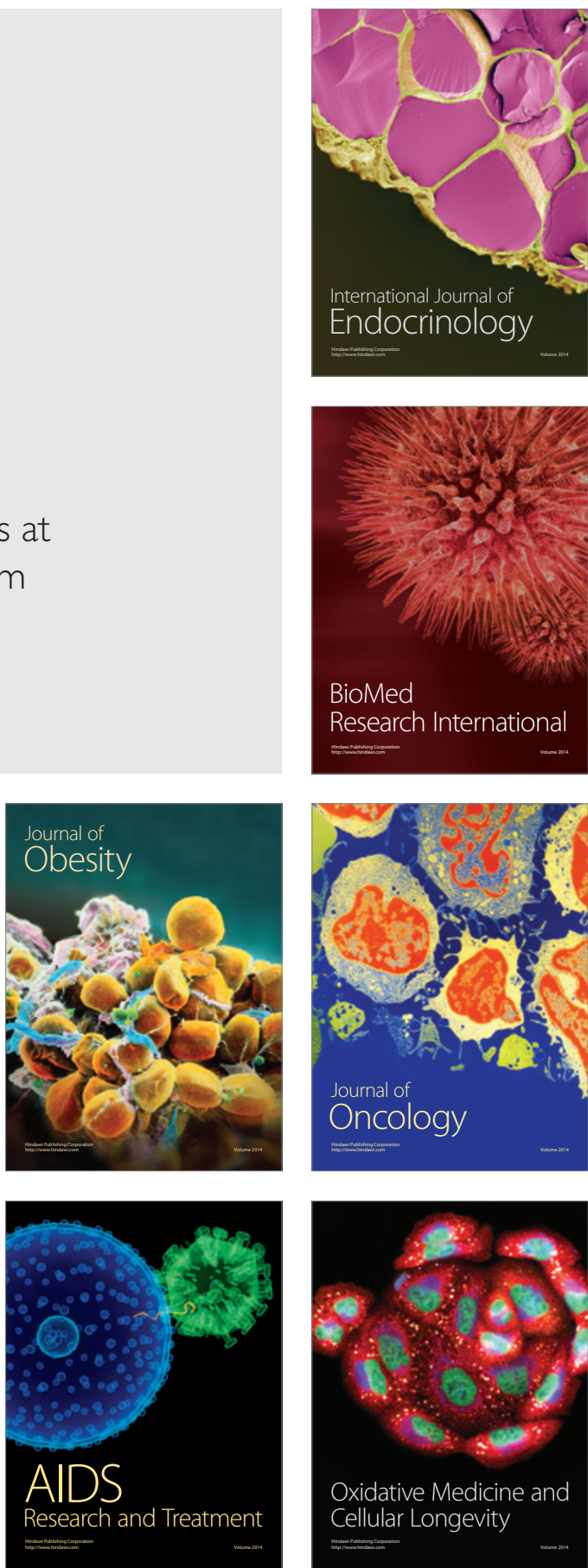